\title{
A mediação das relações sociais nas redes sociais virtuais: do ciberespaço ao ciberterritório
}

\author{
Rubens Staloch \& Clovis Reis \\ Universidade do Estado de Santa Catarina / Universidade Regional de Blumenau \\ E-mail: rubens.staloch@udesc.br/professorclovisreis@gmail.com
}

\begin{abstract}
Resumo
As tecnologias da informação e da comunicação auspiciam o debate sobre as novas formas de organização social e o desenvolvimento de um novo conceito de território, considerando que este se modifica espaço-temporalmente através da organização humana. A partir de tal premissa, o presente trabalho discute a inserção das redes sociais virtuais (RSVs) na mediação das relações sociais. Postulase que o território é o resultado da im-

quais são mediadas no ciberespaço, por exemplo, através das redes sociais virtuais. O percurso teórico-metodológico culmina com o delineamento inicial do conceito de ciberterritório. A proposta não esgota o diálogo sobre o tema. O objetivo é abrir horizontes para novas discussões, que facilitem o entendimento sobre o alcance das dinâmicas sociais recentes, desenhadas no âmbito do ciberespaço.
\end{abstract} pressão das relações sociais no espaço, as

Palavras-chave: Redes sociais virtuais; ciberespaço; ciberterritório; comunicação.

\section{The mediation of social relationships in virtual social networks: from cyberspace to ciberterritory}

\begin{abstract}
Information and communication technologies sponsor the dialogue on the new forms of social organization and the development of a new concept of territory, considering that this latter changes spatiotemporally through human organization. Based on such premises, the present paper discusses the insertion of vir-

tual social networks (VSNs) on the mediation of social relationships. It is postulated that the territory is the result of the impression of social relations in space, which are mediated, in cyberspace, through virtual social networks. The theoretical and methodological approach ends up with the clarification of the concept
\end{abstract}


of cyber-territory. Our study doesn't discussions, that facilitate the understanexhaust the dialogue about the topic. Its ding about the reach of recent social dygoal is to open up new horizons for new namics occurring in cyberspace.

Keywords: Virtual social lines; cyberspace; cyberterritory; comunication.

\title{
Introdução
}

\begin{abstract}
$\mathrm{A}^{\mathrm{O}}$
analisar a história da humanidade verifica-se que as formas de interação humana eram exclusivamente com pessoas próximas. Desde o final do século XIX, a evolução das tecnologias de informação e comunicação vem se transformando radicalmente e também, os padrões de organização e interação humana. A forma de interação social se transformou de modo que há alterações do controle do espaço.

No final do século $\mathrm{XX}$, as novas tecnologias digitais revolucionaram a comunicação, possibilitando que se compartilhem informações de forma instantânea e simultânea com milhões de pessoas quase em qualquer parte do mundo. Já não é preciso estar próximo fisicamente para manter relações.

Para o presente trabalho, parte-se da premissa de que o território é constituído pelas relações sociais, e então, indaga-se: hoje, sendo as relações sociais dadas no ciberespaço, nas redes sociais virtuais, por exemplo, é possível inferir que há um ciberterritório?

Antes de qualquer ponderação, faz-se uma breve contextualização sobre o conceito de território para que após, se possa formular uma resposta para a pergunta norteadora deste trabalho.

Apesar de ser conceito-chave para a Geografia, o território, também é estudado por demais áreas, cada uma com um enfoque centrado em determinada perspectiva. (Haesbaert, 2007)
\end{abstract}

Enquanto o Geógrafo tende a enfatizar a materialidade do território, em suas múltiplas dimensões (que deve[ria] incluir a interação sociedadenatureza), a Ciência Política enfatiza sua construção a partir de relações de poder (na maioria das vezes, ligada à concepção de Estado); a Economia, que prefere a noção de espaço á de território, percebe-o 
muitas vezes como fator locacional ou como uma das bases da produção (enquanto "força produtiva"); a Antropologia destaca sua dimensão simbólica, principalmente no estudo das sociedades ditas tradicionais (mas também no "neotribalismo" contemporâneo); a Sociologia o enfoca a partir de sua intervenção nas relações sociais, em sentido amplo, e a Psicologia, finalmente, incorpora-o no debate sobre a construção da subjetividade ou da identidade pessoal, ampliando até a escala do indivíduo. (Haesbaert, 2007, p. 37)

É imprescindível entender também que o território está em constante transformação. O entendimento que se tinha deste conceito na Idade Média não é o mesmo do século XX, e esse, por sua vez, não é o mesmo que se tem hoje. O território não se define estritamente pelos seus limites físicos, mas também pela forma como se produz em seu interior, a interação social, demonstrando a relevância dos atores para a construção de relações e dos territórios. Como as relações humanas são dinâmicas, modificam-se espaçotemporalmente, a formação de territórios também tende a sofrer alterações. (Haesbaert, 2007)

Pensar em território requer também entender o espaço. Ambos não são termos equivalentes e nem sinônimos (Raffestin, 2008, p. 26). É fundamental "entender como o espaço está em posição que antecede ao território, porque este é gerado a partir do espaço, constituindo o resultado de uma ação conduzida por um ator que realiza um programa em qualquer nível.” Já, Lefebvre (1992 [1974], p. 26), compreende que as relações sociais não podem ser resumidas ao espaço físico, é o espaço da vida social onde ocorrem as relações entre os seres.

Dessa forma, a base do território é a natureza ou o espaço, onde o homem transforma a partir do seu trabalho, sua intervenção, afirmando que a natureza não produz; ela cria e somente o homem é capaz de produzir através do trabalho. Nestes termos, o modo de produção vigente em cada sociedade é determinante para a produção do espaço. Também, é necessário o entendimento que que não há uma indissociabilidade entre espaço e território. (Lefebvre, 1992 [1974])

Para Raffestin (1993, p. 143), o ator "ao se apropriar de um espaço, concreta ou abstratamente [...] territorializa o espaço", ou seja, o território é modificado pelo trabalho e pelas relações de poder presentes no cotidiano, é um 
espaço onde se projetou um trabalho. Desta forma, as impressões humanas de poder no espaço irão definir o território.

Já para Saquet (2007, p. 77) "o espaço geográfico não é apenas palco, receptor de ações, substrato [...] tem um valor de uso e um valor de troca, distintos significados e é elemento constituinte do território, pois eles são indissociáveis".

Os indivíduos vivem cotidianamente relações sociais, criam relações de poder que se revelam na construção de malhas, nós, redes, que por sua vez, constituem o território, manifestado em diferentes escalas espaço-temporais e sociais, modificando-se no transcorrer do tempo. (Raffestin, 1993)

Estes processos de "composição, decomposição e recomposição dos territórios" se acentuam durante o século XVIII com a Revolução Industrial (Raffestin, 2008, p. 22-23). Essas expressões, ditas de outra forma, constituem uma dinâmica e um movimento constante das conceituações teóricas de território, propiciando o entendimento do que Raffestin (1984, p. 78) apud Saquet (2007, p. 78) e Hasbaert (2006) elencam, a TDR (territorialização, desterritorialização e reterritorialização):

(...) a territorialização implica (...) um conjunto codificado de relações (...), a desterritorialização é, em primeiro lugar, o abandono do território, mas também pode ser interpretada como a supressão dos limites, das fronteiras (...). A reterritorialização (...), pode ocorrer sobre qualquer coisa, através do espaço, a propriedade, o dinheiro etc..

Haesbaert (2007) apresenta pelo menos três enfoques para o conceito de território: a) materialista: onde o território é recurso natural, distância física ou no limite um abrigo; b) idealista: associando território e cultura, uma visão mais simbólica e dos poderes invisíveis; c) e um enfoque integrador entre as diferentes dimensões sociais: naturalista e biológica, relações de poder (Estado-Nação Moderno) e econômica.

Devido a essas diferentes abordagens sobre o território, Haesbaert (2006) enfatiza a existência de uma multiterritorialidade, não-hierárquica e em constante processo de transformação. O território em qualquer compreensão, tem a ver com poder, mas não apenas "poder político" tradicional. Ele diz respeito tanto ao poder no sentido mais concreto, de dominação, quanto ao poder no sentido mais simbólico, de apropriação. 
Hasbaert (2006) ainda diz que há um mito sobre o processo de desterritorialização, ou seja, para ele não há o "fim dos territórios", não há apenas uma desterritorialização, há sempre um processo de territorialização, desterritorialização e re-territorialização - TDR. Uma desterritorialização ocorre devido a interações, sejam elas políticas, culturais, econômicas, e até, naturais, que por sua vez, constituir-se-ão em novas territorialidades, dando início a uma re-territorialização e, assim, caracterizando o movimento da TDR.

Para Saquet (2007) é preciso considerar para o processo de territorialização os quesitos: economia, política, cultura e natureza, considerando ainda, suas relações. O autor aborda a questão de um novo arranjo territorial, com autogestão e autonomia para os sujeitos, sendo que para isso é fundamental compreender e redimensionar as relações de poder que estão no cotidiano de todos.

O território assume distintos significados para diferentes sociedades, o que o caracteriza como dinâmico. As relações de poder são componentes que não podem faltar para a efetivação de um território (Saquet, 2007), que por sua vez “(...) é a cena do poder e o lugar de todas as relações (...)” Raffestin (1993) apud Saquet (2007, p. 34).

Assim, Saquet (2007, p. 127), elenca que "os territórios são produzidos espaço-temporalmente pelo exercício do poder por determinado grupo ou classe social, pelas territorialidades cotidianas." Simultaneamente, as territorialidades são o resultado, condicionantes e dão características da territorialização e do território, porém, não descarta em suas análises a natureza, pois a territorialização é efetivada mediante relações entre a sociedade e a natureza, mediada pelas territorialidades ${ }^{1}$.

As forças sociais efetivam o território, o processo social, no (e com o) espaço geográfico, centrado na territorialidade cotidiana dos indivíduos e emanado dela, em diferentes centralidades, temporalidades e territorialidades, que condicionam nossa vida cotidiana. Formam-se territórios

1. Territorialidade e território não são sinônimos, mas sim, complementares. As territorialidades são definidas, assim como o território, histórico-temporalmente. Em determinados momentos constituem-se a partir de certas relações e em outros momentos se modificam devido as intenções humanas, dando forma a novas configurações, a partir de novas relações sociais, ou seja, resultam de uma construção social formatada espacialmente para um determinado objetivo. Territorialidade então, está diretamente relacionada às interações sociais dos atores, sejam elas, por objetivos políticos, econômicos, etc. 
heterogêneos e sobrepostos fundados em desigualdades e diferenças. Cristalizam-se territorialidades e interesses predominantemente econômicos e/ou políticos e/ou culturais que dão uma certa forma e determinados conteúdos ao território e aos territórios. (Saquet, 2007, p. 128)

De acordo com Sack (2011 [1986]), as territorialidades são constituídas a partir das ações humanas, da tentativa de um indivíduo ou grupo de controlar/influenciar os demais numa área [território] delimitada. Para o autor, as territorialidades são escalares, pois podem ocorrer tanto em níveis do indivíduo, do lar, no trabalho, etc., e, ainda, se alteram de acordo com as relações sociais constituídas.

Quanto ao território, Sack (2011 [1986], p. 78) admite que é um lugar que está sob o controle de uma autoridade, "é uma estratégia para estabelecer diferentes níveis de acesso a pessoas, coisas e relações." Para o autor, o território diz respeito ao "controle de acesso" e esse controle de acesso é dado mediante as territorialidades.

Como se percebe, a construção dos territórios perpassa por diversas questões, de diferentes áreas. Além dos aspectos políticos, Santos (2002 [1996]) também salienta a importância dos aspectos sociais, econômicos e culturais entrelaçados em virtude do movimento da sociedade [territorialidades] no decorrer dos diversos momentos históricos e do desenvolvimento das técnicas na compreensão do território.

Impulsionados pelas tentativas de compreender fenômenos e processos sociais e territoriais, demonstrando a existências de redes de circulação e comunicação, identidades e relações de poder, "no Brasil, tanto a expansão como a qualificação de estudos centrados nos conceitos de território e territorialidade ocorrem, principalmente, a partir do biênio 1992-93", com a participação de autores em seminários internacionais. (Saquet, 2007, p. 120)

Para compreender a constituição dos territórios e das territorialidades, de uma forma resumida, elencou-se as principais características, que por sua vez, são delineadas da seguinte forma: 
A mediação das relações sociais nas redes sociais virtuais: do ciberespaço ao ciberterritório

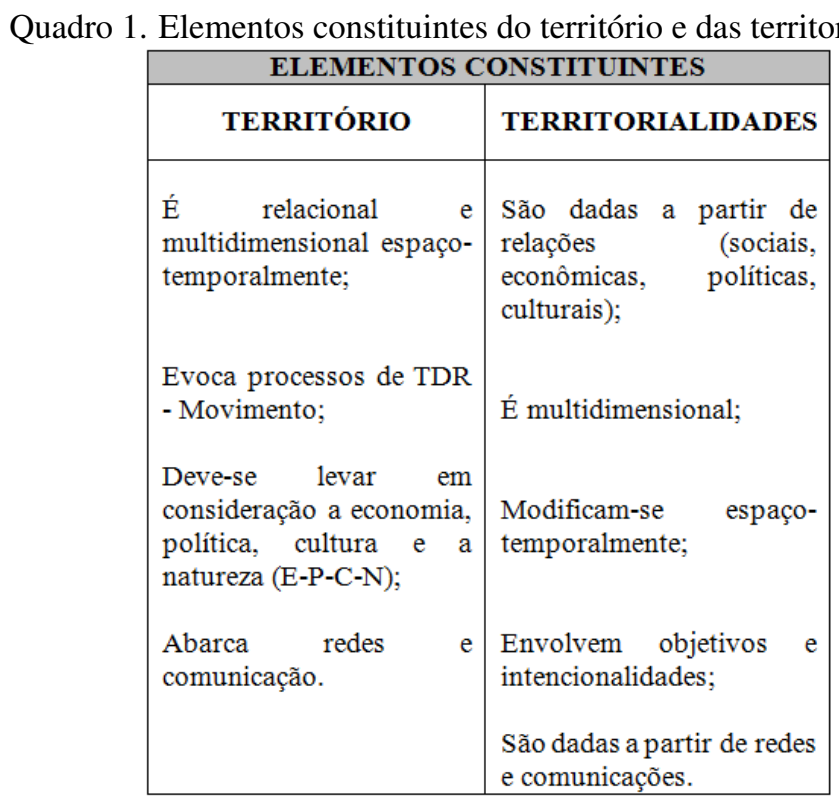

Fonte: Elaborado pelos autores

A desterritorialização está intimamente ligada ao processo de modernidade e globalização, ao período técnico-científico. Saquet (2007) evidencia a formação das redes de circulação e de comunicação como contribuição para o controle do espaço. Elas "agem como elementos mediadores da reprodução do poder da classe hegemônica e ligam o singular ao universal (e vice-versa), interferindo diretamente na territorialidade dos indivíduos e das classes sociais." (Saquet, 2007, p. 129)

Essa desterritorialização possui suas bases no discurso da(s) mobilidade(es), tanto material quanto imaterial, "especialmente aquela diretamente ligada aos fenômenos da compreensão tempo-espaço, propagada pela informatização através do chamado ciberespaço" (Haesbaert, 2006, p. 236).

Desta forma, Haesbaert (2006, p. 270) propõe uma interpretação do território como um híbrido entre a materialidade a imaterialidade, funcionalidade e expressividade, demonstrando que há sempre um processo de territorialização e desterritorialização. 
A diferença está no fato de que nas sociedades disciplinares (mais tradicionais) estão amparadas na dimensão concreta do espaço, enquanto nas sociedades mais modernas estão amparadas em uma dimensão mais abstrata, informacional e organizada em rede decorrente das tecnologias da informação e da comunicação (Castells, 1999). Assim, entende-se que há diferentes perspectivas de territórios, o que Haesbaert (2006) entende por multiterritorialidade:

Multiterritorialidade (ou multiterritorialização se, de forma mais coerente, quisermos enfatizá-la enquanto ação ou processo) implica assim a possibilidade de acessar ou conectar diversos territórios, o que pode se dar tanto através de uma "mobilidade concreta", no sentido de um deslocamento físico, quanto "virtual", no sentido de acionar diferentes territorialidades mesmo sem deslocamento físico, como nas novas experiências espaço-temporais proporcionadas através do ciberespaço.

(Haesbaert, 2006, p. 341-341)

Não se trata apenas de uma transformação meramente quantitativa, mas sim, de "mais alternativas territoriais, maior facilidade de acesso, maior velocidade de mudança" (Haesbaert, 2006, p. 345). Devido a essas novas articulações territoriais, embasadas no ciberespaço, surgem os "territórios-rede flexíveis, onde o mais importante é ter acesso aos pontos de conexão que permitem "jogar" com a multiplicidade de territórios existentes, criando assim uma nova territorialidade" (Haesbaert, 2006, p. 345) e, também, constituindose em constantes desterritorializações e reterritorializações.

De acordo com Haesbaert (2006), um dos principais teóricos sobre a desterritorialização no ciberespaço é Lévy (1999, p. 94), que conceitua ciberespaço como sendo "o espaço de comunicação aberto pela interconexão mundial de computadores e das memórias dos computadores", sendo o virtual a marca desse ciberespaço.

Pode-se dizer que estrutura social de uma sociedade resulta da relação existente entre a tecnologia e a forma de organização social num plano mais geral. A comunicação e a organização em rede transcende fronteiras, é global. Difunde-se através do poder integrado nas redes globais (Castells, 1999). Desse modo, "territorializar-se significa também, hoje, construir e/ou controlar fluxos/redes e criar referenciais simbólicos num espaço em movimento, no e pelo movimento" (Haesbaert, 2006, p. 280). 
De forma geral, os territórios são relacionais e multidimensionais espaçotemporalmente; Evocam movimento, - processos de TDR; Deve-se levar em consideração a economia, política, cultura e a natureza em sua formatação e abarca redes e comunicação.

Assim sendo, o território como um produto social, relacional e histórico pode também ser condicionado e idealizado de forma virtual, no ciberespaço? Ou melhor, é possível inferir que hoje, com as tecnologias da informação e comunicação e da internet, e das relações sociais nas redes sociais virtuais, existe um ciberterritório?

Tentando responder esta pergunta, o presente trabalho pautou-se em fazer, na próxima seção, uma abordagem sobre o conceito de ciberespaço e a formatação das redes sociais virtuais neste.

Após, discute-se o conceito de ciberespaço e as relações sociais construídas pelas redes sociais virtuais (RSVs), para que seja possível correlacionar a formação de territórios a partir de relações mediadas pelo computador, mais precisamente, através da RSVs no ciberespaço, dando um delineamento no conceito de ciberterritório.

\section{Ciberespaço e redes sociais virtuais}

Estudos demonstram que a internet pode contribuir para a interação social online e off-line de forma muito significativa. Por mais que existam céticos com relação a utilização da internet para a mediação das relações, pesquisas mostram que os usuários conectados conversam muito mais por outros meios, inclusive, por telefone, do que pessoas que não estão conectadas a rede. Sendo assim, a questão colocada de que a internet [diga-se também, as relações no ciberespaço] acaba colocando os atores em isolamento social se desfaz. (Katz et al., 2001)

O ciberespaço é "o espaço de comunicação aberto pela interconexão mundial de computadores e das memórias dos computadores", sendo o virtual a marca desse. (Lévy, 1999, 94)

O termo especifica não apenas a infraestrutura material da comunicação digital, mas também o universo oceânico de informações que ela abriga, assim como os seres humanos que navegam e alimentam esse universo. Quanto ao neologismo (materiais e intelectuais), de práticas, 
de atitudes, de modos de pensamento e de valores que se desenvolvem juntamente com o crescimento do ciberespaço. (Lévy, 1999, p. 17)

Esse ciberespaço está pautado na virtualização, que não é uma desrealização, o que aumenta os graus de liberdade. Lévy (1999) diz que a virtualização pode ser encarada como um sinônimo de desterritorialização quando "o ciberespaço encoraja um estilo de relacionamento quase independente dos lugares geográficos [...] e da coincidência dos tempos.” (Lévy, 1999, p. 51)

Surgem novas territorializações embasadas na organização em rede, descritas por Castells (1999), que tem como características a mobilidade ou o movimento. As territorialidades, assim como as tecnologias são multidimensionais. As tecnologias, principalmente a estruturação de comunicações via internet, começam a tomar forma nos anos de 1960, emergindo um novo paradigma tecnológico, o da comunicação online. Para Castells (1999), a tecnologia não define a sociedade, ela é a sociedade, inclusive, possibilitando relações de poder.

É importante ressaltar que o conceito de redes não é uma exclusividade do universo tecnológico. Não se constituem apenas devido às tecnologias da informação e comunicação (TICs). São formas muito antigas de práticas humanas. Os seres humanos estão inseridos em uma sociedade através de relações que constroem ao longo de suas vidas, primeiro no âmbito familiar, escolar, no trabalho, etc., e, assim, a própria natureza humana nos conduz a uma estrutura de organização em rede.

Watts (2009, p. 11) conceitua rede como sendo "um conjunto de objetos conectados entre si de certo modo". Quando se fala em rede, podemos falar tanto de uma grande empresa, de roteadores na internet ou até de neurônios, porém, todas estas possuem formas distintas umas das outras.

Todos os organismos vivos são uma rede, desde o corpo até a relação com os demais seres e com a própria natureza. O padrão de rede é um dos padrões de organização mais básico de todos os sistemas vivos. (Capra, 1996, 2001)

Em todos os níveis da vida existem redes de conexões, de interligação, desde o sistema metabólico do corpo até as teias alimentares dos ecossistemas. Dessa forma, Capra (1996) chama a atenção para o fato de que os componentes e os sistemas vivos se interligam sob a forma de rede.

Embora a metáfora descrita por Capra (1996) possa ajudar na compreensão da estrutura em rede, não podemos transportá-la para o domínio social 
sem antes considerar as características que a definem. Para entender o sistema metabólico do corpo humano é preciso, antes de tudo, entender que este é um padrão não-linear de organização. É preciso entender de biologia molecular e de bioquímica para compreender a natureza das conexões e suas funções dentro do sistema.

Assim, também se deve fazer para analisar uma rede social que, por sua vez, é um sistema não-linear de organização. Os nós e as conexões dessas redes, diferentemente da rede molecular, não são dadas a partir de elementos bioquímicos, mas sim, de elementos sociais, envolvendo a história, a cultura, a linguagem, a comunicação, fenômenos, etc..

As redes sociais são dadas por conexões, diretas e indiretas, que ligam uma pessoa ou grupo a outras pessoas ou grupos. Estas podem ser constituídas de forma direta quando incluem pessoas que você conhece (amigos) e, indireta quando são formadas por relações de "segundo grau" (amigos de amigos).

No momento em que se vive, a organização social está pautada em torno de novos padrões em rede, pois, são constituídas através de meios de comunicação. Como redes sempre remetem a agrupamentos, a coletivos com uma dinâmica desenvolvida para que ocorra sempre a interação entre os atores, as tecnologias digitais ocupam um papel central nas profundas mudanças experimentadas em todos os aspectos da vida social, constituindo novos paradigmas. (Recuero, 2011)

As relações sociais contemporâneas estão se modificando devido à utilização destas tecnologias, principalmente da internet na composição de redes de comunicação e interação, as chamadas redes sociais. (Recuero, 2011)

De acordo com Castells (1999), as tecnologias da informação e comunicação são sensíveis aos usos sociais. A tecnologia é condição necessária, mas, não somente para a emergência de uma organização social baseada em redes, nós, conexões. É necessária a adaptação e a vivência dos agentes (indivíduos) nessa nova forma de organização.

Para que se chegasse nos atuais modos de interação via internet foi necessário uma série de novos conhecimentos e inovações tecnológicas que demorou mais de 30 anos para se desenvolver. Ao final de 1995, que foi o primeiro ano em que a internet foi amplamente utilizada e disseminada, havia 16 milhões de usuários (Castells, 2003). Já, em 2014, de acordo com o site Internet 
World Stats $^{2}$ havia em dezembro de 2013 quase 3 bilhões de usuários, o que representa um nível de penetração da internet na ordem de 39\%.

A chegada da internet, então, significa que os dados podem ser processados de forma muito rápida em quase qualquer parte do mundo, não existindo a proximidade física entre os indivíduos envolvidos ou conectados, surgindo assim o ciberespaço.

Presume-se que a partir do desenvolvimento dos meios de comunicação e informação, da internet, as relações sociais passaram a ser organizadas não mais delimitadas a um espaço físico ou geográfico, mas sim, essas relações passaram a ocorrem independentes de tempo e espaço. Passaram a ocorrem em um ciberespaço, em grande parte, após os anos 2000, nas redes sociais virtuais. (Recuero, 2011)

Recuero (2011) propõe-se a pensar nessas redes e reconhece-as como agrupamentos complexos instituídos por interações sociais, apoiadas em tecnologias digitais, para pensar os aspectos individuais, coletivos e tecnológicos dos agrupamentos humanos na rede de internet, em um denominado ciberespaço. $\mathrm{Na}$ internet os dados podem ser processados de forma muito rápida em quase qualquer parte do mundo, não existindo a necessidade de proximidade física entre os indivíduos envolvidos ou conectados, eis o ciberespaço.

O ciberespaço representa o resultado de um movimento internacional de jovens com vontade de experimentar coletivamente formas de comunicação diferente daquelas que a mídia clássica propõe. Dessa forma, é "o novo meio de comunicação que surge da interconexão mundial de computadores." (Levy, 1999, p. 17)

Lévy (1999, p. 94) define-o como "o espaço de comunicação aberto pela interconexão mundial de computadores e das memórias dos computadores", permitindo vários modos de comunicação. Três são os princípios básicos que orientam o crescimento inicial do ciberespaço: "a interconexão, a criação de comunidades virtuais e a inteligência coletiva." (Lévy, 1999, p. 129)

Essa interconexão mundial de computadores, designada ciberespaço, remodela a sociedade, pois causa um impacto social e cultural muito forte, tanto positivamente, quanto negativamente, principalmente na discussão sobre o poder, como aborda Lévy (1999). A revolução da tecnologia está remodelando

2. Internet World Stats. Disponível em:www.internetworldstats.com. Acesso em: 01 de outubro de 2014. 
a base material da sociedade, apresentando uma nova forma de relação entre a economia, o Estado e a sociedade, onde "as redes interativas de computadores estão crescendo exponencialmente criando novas formas e canais de comunicação, moldando a vida e, ao mesmo tempo, sendo moldadas por ela." (Castells, 1999, p. 22)

Inclusive, pode-se dizer que há uma relação híbrida entre as relações nos lugares físicos e no ciberespaço. Nesse sentido há uma interpenetração, entre o on-line e o off-line, conforme descreve Malini (2013). O ciberespaço fez com que a rua e a rede se interpenetrassem, surgindo uma política colaborativa e em tempo real. Para o autor, o ciberespaço é um ambiente virtual comunitário e participativo de grupos de discussão.

Em seu livro "A Internet e a rua", Malini (2013) destaca, com base nos protestos ocorridos no Brasil e no mundo, a hipótese de que a rua e a rede se interpenetram, fazendo surgir uma relação direta e em tempo real, há uma interpenetração. No caso de movimentos sociais, tal interpenetração ocorre de uma forma tão simbiótica que a rua e a rede parecem uma só.

Desta forma, a internet foi apropriada por se tornar um espaço constante de tensão de diferentes movimentos e poderes, culminando em uma mobilização global político-afetiva, nas ruas e nas redes (Malini, 2013), como pode ser observado nos movimentos da Primavera Árabe, Occupy Wall Strett, 15M na Espanha e nas mobilizações no Brasil em junho de 2013, todas desencadeadas de forma on-line, mais precisamente, através de redes sociais virtuais e também interpenetradas com as ruas.

Se pode dizer que a internet não é o futuro, mas sim, o presente. Essa tecnologia é muito mais do que uma tecnologia, é um meio de comunicação, de interação e organização social, assim, pode-se dizer que a emergência da internet como meio de comunicação fez com que ocorresse uma nova interpretação, como culminação de um processo histórico de desvinculação entre localidade e sociabilidade na formação da comunidade: "novos padrões, seletivos, de relações substituem as formas de interação humanas territorialmente limitadas." (Castells, 2003, p. 98)

A internet "é uma extensão da vida como ela é, em todas as suas dimensões e sob todas as suas modalidades" (Castells, 2003, p. 100). Nesse sentido, as redes que se formam no ciberespaço são constituídas através da comunicação, pela linguagem simbólica, por relações construídas espaço- 
temporalmente. Assim, "estudar redes sociais, [...] é estudar os padrões de conexões expressos no ciberespaço." (Recuero, 2011, p. 21)

Falar em rede social implica falar em elementos essenciais à construção delas, sendo eles os atores e as conexões. Os atores são o primeiro elemento de uma rede social. São as pessoas envolvidas na rede que se analisa. "Como partes do sistema, os atores atuam de forma a moldar as estruturas sociais, através da interação e da constituição de laços sociais." (Recuero, 2011, p. 25)

Devido ao distanciamento físico entre os atores sociais, eles não são imediatamente discerníveis, mas há sempre um processo de construção de identidade e expressão por parte dos atores no ciberespaço. Os sites de redes sociais, que são Softwares Sociais, com aplicação direta para a comunicação mediada por computador", como o Myspace, Twitter e Facebook são formas de apropriação de espaços por parte dos atores. "Funcionam como uma presença do "eu" no ciberespaço, um espaço privado e, ao mesmo tempo público". (Recuero, 2011, p. 27)

Mas como é possível compreender a interação social no ciberespaço? São vários os elementos que precisam ser considerados para isso. Recuero (2011, p. 31) coloca que "o ciberespaço e as ferramentas de comunicação possuem particularidades a respeito dos processos de interação", por isso, a importância dos estudos das redes sociais virtuais (RSV).

A interação é construída pela mediação do computador, possuindo com característica de migração, ou seja, "as interações entre os atores sociais podem [...] espalhar-se entre as diversas plataformas de comunicação" (Recuero, 2011, p. 36). A interação é geradora de laços sociais, fortes ou fracos.

São laços fortes, quando "se caracterizam pela intimidade, pela proximidade e pela intencionalidade em criar e manter uma conexão entre duas pessoas". Já, os laços fracos são dados "por relações esparsas, que não traduzem proximidade e intimidade" (Recuero, 2011, p. 41). Desta forma, a relação/interação é considerada a unidade básica de uma rede social. Porém, "uma relação sempre envolve uma quantidade grande de interações". (Recuero, 2011, p. 37)

O desenvolvimento tecnológico proporcionou uma certa flexibilidade na manutenção e criação de laços sociais, uma vez que permitiu que eles fossem dispersos espacialmente. Isso quer dizer que a comunica- 
ção mediada por computador apresentou às pessoas formas de manter laços sociais fortes mesmo separadas a grandes distâncias, graças a ferramentas como o Skype [...] Essa desterritorialização dos laços é consequência direta da criação de novos espaços de interação. (Recuero, 2011, p. 44)

As redes sociais virtuais (RSV) são denominadas assim, pois as relações, interações e conexões entre os atores são desencadeadas através da comunicação mediada pelo computador, num plano virtual, no ciberespaço. Os principais atributos das RSV são: a sua dinamicidade; capacidade de constituir comunicação horizontalizada; os indivíduos podem se organizar de forma autônoma; possibilitam múltiplas conexões e são potencializadoras, pois, assumem papel potencializador em ações desempenhadas pelos indivíduos.

Importante ressaltar que as relações não precisam ser formadas apenas de interações que construam ou acrescentam algo, podem também ser formadas a partir de interações conflituosas. "A ideia de relação social é independente do seu conteúdo" (Recuero, 2011, p. 37).

No ciberespaço, através das RSVs as relações humanas estão se modificando, demonstrando que o mundo está em constante processo de transformação estrutural e social. Como o território não se define estritamente pelos seus limites físicos, mas, também, pela forma como se produz, em seu interior, a interação social, assim, demonstrando a relevância dos atores para a construção das territorialidades e dos territórios.

Se as relações sociais são dadas pela interação humana em determinado período de tempo e sob objetivos e intencionalidades, hoje, constata-se que as relações estão mediadas no ciberespaço. Como o território é constituído pelas interações humanas, pelas relações de poder, econômicas, sociais, etc., é possível dizer que a partir das relações mediadas pelas RSVs há a constituição de um ciberterritório? Para delinear uma possível afirmação, a próxima seção se propõe a correlacionar o que os assuntos descritos até então.

\section{Ciberespaço, redes sociais virtuais e a constituição de ciberterritório}

Hoje, há a constituição de relações sociais entre os indivíduos, mesmo estando em territórios físicos distantes, de forma horizontalizada, autônoma e automediada. Pode-se dizer que há uma nova territorialidade, num ciberespaço, estreitando os laços entre os indivíduos. "Os vínculos cibernéticos 
colaboram para que as pessoas, que antes teriam vidas sociais mais limitadas, tenham contatos mais diversificados pelas redes" (Labadessa, 2012, p. 84), tornando as territorialidades, não mais limitadas fisicamente e, sim, expandidas ao ciberespaço que, por sua vez, é um agente de libertação.

É tudo construído pela mediação do computador. Essa interação social no ciberespaço pode se dar de forma síncrona ou assíncrona. Síncrona quando simula uma interação em tempo real, como nos canais de chat ou, mesmo, nos bate-papos das redes sociais virtuais. São interações em que ambos os atores estão presente, no mesmo momento em uma mesma conexão. (Recuero, 2011)

Já, as interações assíncronas, são aquelas que permanecem mesmo quando os atores estão desconectados do ciberespaço, por exemplo, o e-mail e os fóruns, onde a expectativa de resposta não é imediata. (Recuero, 2011)

Uma RSV é disseminada nos sites de redes sociais. Recuero (2011, p. 102) define-os como "os espaços utilizados para a expressão das redes sociais na internet", ou seja, permitem a visibilidade, a articulação das redes sociais e a própria manutenção dos laços sociais existentes no espaço off-line. Os sites de redes sociais permitem a expressão da rede social.

Uma rede social é sempre um conjunto de atores e suas relações, ou seja, suas conexões. A RSV - no ciberespaço - no âmbito dos indivíduos possibilita novas combinações de emprego e trabalho autônomo, expressão individual, cooperação e sociabilidade e, para os ativistas políticos, ela tornará possível que redes de indivíduos se combinem e cooperem para disseminar sua mensagem no mundo, conforme elenca Castells (2013).

Nesse ciberespaço, as redes sociais virtuais encorajam os indivíduos a se relacionarem uns com os outros, independentemente da localização geográfica em que estão. Assim é a estrutura organizacional que define essa era (Castells, 1999): a organização em rede, dadas através das tecnologias da informação e comunicação, revolucionando a maneira como os indivíduos interagem, como se mobilizam e como podem constituir territorialidades.

É preciso, ainda, entender que nenhuma rede social é estática; está em constante movimento, portanto, é dinâmica. Assim, uma RSV também possui tais características, suas estruturas, as conexões e formas de relacionamentos podem ser alteradas ao longo dos tempos e dos modos de vida de cada ator, diz-se que as estruturas se modificam devido à dinâmica existente nestas RSVs. 
Através destas redes, os indivíduos podem inclusive se organizarem em comunidades virtuais, que nada mais é, do que um grupo de pessoas que estabelecem entre si relações sociais, que permanecem um tempo suficiente para que elas possam constituir um corpo organizado, através da comunicação mediada por computador (Recuero, 2011), que estão carregadas de interesses, por isso, os indivíduos, são cooperativos, independentemente da localização geográfica em que estão. (Lévy, 1999)

As comunidades virtuais podem ser elencadas como uma forma de organização na cibercultura, descrita por Lévy (1999), gerando uma forma de cooperação básica e necessária para a formação de RSV. Porém, o conflito é igualmente frequente nas RSV, principalmente quando existem atores dentro de determinada rede que, por exemplo, em uma determinada postagem de um ator A, um ator B comenta de forma ofensiva e agressiva, contrariando-se sobre a postagem. O conflito imediatamente surge.

Os conflitos, em uma RSV não são totalmente negativos. Em muitos casos são positivos, pois são estes que possibilitam as discussões e as interações entre os atores, tornando a rede mais dinâmica. "Esses processos dinâmicos são, portanto, essenciais para a percepção das redes sociais no tempo e sua compreensão, enquanto elementos não estáticos". (Recuero, 2011, p. 86)

Quando ocorre a criação de um grupo, por exemplo, no Facebook, há a interação social entre os atores, porém, há muito mais do que isso. Existe neste grupo uma RSV que expressa a identidade dos atores, constituindo-se assim, uma forma de mostrar quem se é no sistema. Cada ator que se engaja na rede se une a ela de forma a cooperar, porém, surgem naturalmente as competições e os conflitos.

Não se pode esquecer de que "os sistemas sociais e as redes sociais, [...] estão em constante mudança" (Recuero, 2011, p. 88), pois, como já elencado no decorrer do trabalho, as redes são sempre redes vivas, incluindo RSV.

Logo, se os territórios são constituídos pelas relações sociais, diga-se, pelas territorialidades, formatadas em diferentes tempos, por que não dizer que hoje, com a ascensão das relações a partir das RSVs, há a constituição de ciberterritórios?

Para tentar demonstrar que isso é possível, faz-se uma correlação entre os quesitos que delineiam os territórios e como tais podem ser delineados no ciberespaço através das RSVs. 
Quadro 2. Correlação dos elementos constituintes do território e a sua delineação no

\begin{tabular}{|c|c|}
\hline TERRITÓRIO & DELINEAÇÃO NO CIBERESPAÇO \\
\hline $\begin{array}{l}\text { É relacional } \\
\text { multidimensional espaço- } \\
\text { temporalmente; }\end{array}$ & $\begin{array}{l}\text { No ciberespaço, através das RSVs, os processos de } \\
\text { constituição dos territórios também são relacionais e } \\
\text { multidimensionais espaço-temporalmente. O ciberespaço não } \\
\text { é apenas um fenômeno das tecnologias, é uma revolução no } \\
\text { modo de pensar o espaço e viver nele. A cada dia é possível } \\
\text { se conectar com novos indivíduos distantes fisicamente, ou } \\
\text { seja, é possível "[...] a transposição de fronteiras territoriais, } \\
\text { articulando as ações locais às regionais, nacionais e } \\
\text { transnacionais; temporais [...]". (WARREN, 2006, p. 126- } \\
\text { 127) }\end{array}$ \\
\hline $\begin{array}{l}\text { Evoca processos de } \\
\text { movimento - TDR; }\end{array}$ & $\begin{array}{l}\text { Se os territórios evocam processos de movimento, nas RSVs } \\
\text { no ciberespaço, estes movimentos são muito mais dinâmicos } \\
\text { e rápidos, pois fluem através das redes de internet. }\end{array}$ \\
\hline $\begin{array}{lr}\text { Devem-se } & \text { levar } \\
\text { consideração } & \text { relações } \\
\text { econômicas, } & \text { políticas, } \\
\text { culturais e naturais; }\end{array}$ & $\begin{array}{l}\text { No ciberespaço, as relações econômicas, políticas, culturais e } \\
\text { naturais podem ser formatadas mediante a conexão dos } \\
\text { computadores, ou seja, "a extensão do ciberespaço } \\
\text { acompanha e acelera uma virtualização geral da economia e } \\
\text { da sociedade" (LÉVY, 1999, p. 51) }\end{array}$ \\
\hline Abarca redes e comunicação. & $\begin{array}{l}\text { Para a constituição dos territórios é necessária a constituição } \\
\text { de redes, basicamente de comunicação. Através das RSVs no } \\
\text { ciberespaço, tais redes, são, antes de tudo, um instrumento de } \\
\text { comunicação, e assim, podem dar origem a um universal por } \\
\text { contato. Pode conectar os espaços (LÉVY, 1999) e os } \\
\text { indivíduos. }\end{array}$ \\
\hline
\end{tabular}

Fonte: Elaborado pelos autores

Dessa forma, delineando um conceito, o ciberterritório poderia ser entendido como o espaço, não-físico, de interação social, assim como no território físico, porém, mediado pelas redes e conexões no ciberespaço, onde se inserem os diálogos, as mobilizações ${ }^{3}$, as ações e os conflitos inerentes de uma sociedade, não descartando que transformações sociais possam ocorrer em decorrência destas interações.

3. Diversos são os movimentos sociais que emergiram das redes sociais virtuais no ciberespaço, dentre os que podemos destacar: Primavera Árabe; Occupy Wall Street; Movimento 15M na Espanha e as Mobilizações ocorridas no Brasil em junho de 2013. (Castells, 2013) e (Malini, 2013) 
Assim, "há núcleos de redes da internet, em âmbito local e global, e há redes pessoais, vibrando ao ritmo de um novo tipo de revolução, cujo ato mais revolucionário é sua própria invenção". (Castells, 2013, p. 116). Verificase então, que a forma como os indivíduos se organizam, hoje, já é um novo produto, uma nova forma de interação dos atores sociais através de uma autocomunicação em massa dadas nas redes sociais virtuais no ciberespaço, que por sua vez, podem resultar na constituição de um ciberterritório.

\section{Considerações}

A comunicação possibilita que se compartilhem informações instantânea e simultaneamente entre os indivíduos. Após o século XIX, mais precisamente, no século XXI, a tecnologia tem possibilitado modificações radicais nos processos de comunicação, e, por consequência, nos processos de interação social também.

Hoje, conforme Castells (1999), "a rede é a mensagem". Mas, o que isso quer dizer, de fato? Como a vida cotidiana dos indivíduos é mediada pelas comunicações, seja gestual, escrita ou fonética, assim, o que Castells (1999) elenca é que as relações sociais se modificaram com a chegada das tecnologias da informação e comunicação, mais precisamente, os avanços da internet. Esse feito possibilitou que uma nova infraestrutura comunicacional emergisse, organizada em rede, no ciberespaço.

Também, nesse ciberespaço, estão as RSVs - redes sociais virtuais -, que possibilitam a organização e difusão de mensagens via internet, dando o caráter organizacional em rede que Castells (1999) destaca. Através destas redes, os indivíduos podem, inclusive, se organizarem em comunidades virtuais com propósitos específicos, como por exemplo, para a realização de mobilizações sociais.

Mas, de que forma toda esta organização se relaciona com a formação dos territórios, ou melhor, de um ciberterritório?

Se, os territórios são o resultado da impressão das relações sociais no espaço, e, no ciberespaço, estas relações são virtuais, dadas, por exemplo, através das RSVs, há uma desterritorialização, dos espaços físicos, para uma re-territorialização, no espaço virtual, onde os indivíduos constituem relações sociais, dinâmicas, automediadas e livres de qualquer poder, que por sua vez, é uma das principais características da internet. 
Sendo assim, se existe uma relação social mediada no ciberespaço, unindo todos os conceitos e temas abordados no trabalho aqui exposto, reitera-se, após o percurso teórico-metodológico, que é possível o delineamento de um ciberterritório: o espaço, não-físico, de interação social, assim como no território físico, porém, mediado pelas redes e conexões no ciberespaço, onde se inserem os diálogos, as mobilizações, as ações e os conflitos inerentes de uma sociedade, não descartando que transformações sociais possam ocorrer em decorrência destas interações.

Não se teve como objetivo esgotar os diálogos sobre o assunto, muito pelo contrário, o intuito é abrir horizontes para novas discussões, que possam contribuir para o entendimento das dinâmicas sociais recentes, desenhadas no âmbito do ciberespaço.

\section{Referências}

Capra, F. (1996). A teia da vida: uma nova compreensão científica dos sistemas vivos. São Paulo: Cultrix/Amana-Key.

Capra, F. (2001). Conexões ocultas. São Paulo: Cultrix/Amana-Key.

Castells, M. (2003). A galáxia da internet: reflexões sobre internet, negócios e sociedade. Lisboa: Fundação Calouste Gulbenkian.

Castells, M. (1999). A sociedade em rede. São Paulo: Paz e Terra.

Castells, M. (2013). Redes de indignação e esperança: movimentos sociais na era da internet. Rio de Janeiro: Zahar.

Haesbaert, R. (2006). O mito da desterritorialização: do "fim dos territórios" à multiterritorialidade. Rio de Janeiro: Bertrand Brasil.

Haesbaert, R. (2007). Definindo território para entender desterritorialização. In M. SANTOS, Território, territórios: ensaios sobre o ordenamento territorial. Rio de Janeiro: Lamparina.

Internet World Stats. Disponível em: www.internetworldstats.com. Acesso em: 01 de outubro de 2014.

Katz, J.; Rice, R.E. \& Aspden, P. (2001). The internet, 1995-2000: Access, Civic Involvement, and Social Interaction. American Behavioral Scientist, 45 . 
A mediação das relações sociais nas redes sociais virtuais: do ciberespaço ao ciberterritório

Labadessa, E. (2012). O uso das redes sociais na internet na sociedade brasileira. Revista Metropolitana de Sustentabilidade - RMS, São Paulo, maio/ago, 2(2): 82-94.

Lefebvre, H. (1992) [1974]. The production of the space. Oxford: Blackwell.

Levy, P. (1999). Cibercultura. São Paulo: Ed. 34.

Malini, F. (2013). A internet e a rua: ciberativismo e mobilizações nas redes sociais. Porto Alegre: Sulina.

Raffestin, C. (1993). Por uma geografia do poder. São Paulo: Ática.

Raffestin, C. (2008). A produção das estruturas territoriais e sua representação. In M.A. Saquet, Territórios e territorialidades: teorias, processos e conflitos. Expressão Popular: UNESP. Programa de Pós Graduação em Geografia.

Recuero, R. (2012). A rede é a mensagem: efeitos da difusão de informações nos sites de rede social. In E. Vizer (Org.). Lo que Mcluhan no previó, vol. 1 (pp. 205-223), $1^{a}$ ed. Buenos Aires: Editorial La Crujía.

Recuero, R. (2001). Comunidades virtuais: uma abordagem teórica. Seminário internacional de comunicação, 5., Santa Catarina, RS. Anais... Santa Catarina, RS. Disponível em: http://pontomidia.com.br. Acesso em: 27 de novembro de 2013.

Recuero, R. (2011). Redes sociais na internet. Porto Alegre: Sulina.

Sack, R.D. (1986). O significado de territorialidade. In L.C. Dias \& M. Ferrari, Territorialidades humanas e redes sociais. Florianópolis : Insular.

Santos, M. (2002) [1996]. A natureza do espaço. São Paulo: Edusp.

Santos, M. (2007). Território, territórios: ensaios sobre o ordenamento territorial. Rio de Janeiro: Lamparina.

Saquet, M.A. (2007). Abordagens e concepções de território. São Paulo: Expressão Popular.

Saquet, M.A. (2004). O território: diferentes interpretações na literatura italiana. In A.D. Ribas, E.S. Sposito \& M.A. Saquet, Território e Desenvolvimento: diferentes abordagens. Francisco Beltrão: Unioeste.

Saquet, M.A. (2008). Territórios e territorialidades: teorias, processos e conflitos. Expressão Popular: UNESP. Programa de Pós-Graduação em Geografia. 
Saquet, M.A. (2011). Por uma abordagem territorial. In M.A. Saquet, Por uma geografia das territorialidades e das temporalidades. São Paulo: Expressão Popular .

Warren, I.S. (2006). Das mobilizações às redes de movimentos sociais. Sociedade e Estado, Brasília, jan./abr, 21(1): 109-130.

Watts, D.J. (2009). Seis graus de separação: a evolução da ciência de redes em uma era conectada. São Paulo: Leopardo. 